\title{
高速铁路路堤传递地基差异沉降特性 及控制限值研究
}

\author{
罗强，李铁，王佳敏，陈虎，龙礼斌 \\ 西南交通大学高速铁路线路工程教育部重点实验室，成都 610031 \\ *E-mail: LQrock@home.swjtu.edu.cn \\ 收稿日期: 2014-03-28; 接受日期: 2014-06-03 \\ 国家重点基础研究发展计划(批准号: 2013CB036204)资助项目
}

\begin{abstract}
摘要为研究高速铁路地基差异沉降在路堤中的传递扩散特性, 运用有限元方法, 分析 了路基在小变形条件下地基差异沉降与路基面不均匀变形的映射关系，并在得到土工离心 模型试验校正的基础上，讨论了地基差异沉降模式、路堤高度等因素对路基面不均匀变形的 影响规律. 研究表明: 地基差异沉降在路堤中的扩散程度随地基差异沉降渐变段长度与路 堤高度比值的增大而减小，比值大于 3 5 以后，地基差异沉降与路基面不均匀变形具有良好 的一致性; 路基面不均匀变形与地基差异沉降呈正相关性，并随路堤高度、地基差异沉降渐 变段长度的增加而减小; 基于路基面不均匀变形限值提出了地基差异沉降控制标准，丰富 了高速铁路路基沉降变形控制技术指标体系。
\end{abstract}

关键词

高速铁路

差异沉降

传递扩散特性

不均匀变形

控制标准

有限元方法

\section{1 引言}

控制路基变形是高速铁路的关键技术之一，也 是一个长期困绕工程界的难题 ${ }^{1]}$. 特别是在路基和结 构物连接处、路堤和路堑连接处、路堤底部不同地基 处理措施连接处 ${ }^{[2,3]}$ 等部位易产生的不均匀变形会直 接导致线路的不平顺, 从而影响高速列车的安全平 稳运行. 因此, 过渡段处理措施在高速铁路变形控制 技术中占有十分重要的位置.

近年来高速铁路在我国的快速发展，使得具有 高平顺、高稳定特性的无砟轨道得到了大量应用, 但 其仅能通过扣件调高来保证轨道的几何型位 ${ }^{[2,4,5]}$. 正 因如此, 无砟轨道对路基变形, 特别是对路基不均匀 变形的要求比有砟轨道更为严格. 目前, 我国高速铁
路无砟轨道路基一般地段工后沉降要求控制在 15 $\mathrm{mm}$ 范围内, 过渡段工后沉降差仅允许在 $5 \mathrm{~mm}$ 以内, 并要求不均匀变形折角不大于 $1 / 1000^{[6]}$. 另一方面, 我国的高速铁路路堤通常采用优质填料填筑，而且 压实标准较高,一般变形较小, 路基面的沉降主要由 地基下沉引起 ${ }^{[7]}$. 所以, 在高速铁路建造中需要对地 基沉降，尤其是不均匀沉降进行“毫米级”的严格控 制，这无疑给工程建设带来了严峻挑战.

据此，基于路堤的地基差异沉降特性，建立了错 台式、渐变式两种路堤地基差异沉降模型，运用有限 元方法讨论了高速铁路路基小变形条件下, 地基差 异沉降 $\Delta s$ 在路堤中的传递扩散特性. 同时, 分析了 $\Delta s$ 对路基面不均匀变形的扰动规律, 并以路基面不 均匀变形限值为控制标准得到了 $\Delta s$ 的允许值, 为解

引用格式: 罗强, 李铁, 王佳敏, 等. 高速铁路路堤传递地基差异沉降特性及控制限值研究. 中国科学: 技术科学, 2014, 44: 736-743 Luo Q, Li T, Wang J M, et al. Analysis on conduction characteristics from embankment and control limits of foundation differential settlement for high speed railway (in Chinese). Sci Sin Tech, 2014, 44: 736-743, doi: 10.1360/N092014-00091 
决路堤的地基差异沉降控制问题提供了技术支持.

\section{2 路堤地基差异沉降计算模型}

\section{1 地基差异沉降模式}

由于路堤地基沉降的不均匀性和地基处理方式 不同, 地基差异沉降的形式各有不同. 因此, 提出了 渐变式和错落式两种路堤地基差异沉降计算模型 ${ }^{[8 ~ 10]}$.

渐变式计算模型主要考虑沿线路纵向路堤地基 差异沉降为逐渐变化的情况, 即差异沉降值有一渐 变段, 为连续分布型, 如图 1 所示. 错台式计算模型 (地基差异沉降渐变段长 $l=0 \mathrm{~m}$ ) 主要考虑沿线路纵向 路堤地基差异沉降为错落式分布情况, 即渐变式模 型极端情况.

\section{2 计算条件和模型路堤参数}

考虑到我国高速铁路路基的特点, 计算中作了 如下假定: (1)路堤部分为连续均匀、各向同性体, 路 堤各层采用 Mohr-Coulomb 材料模拟; (2)按平面问题 计算, 即认为路基横向宽度范围内沉降均匀, 只在线 路纵向存在差异沉降; (3)模型路堤除受自身重力荷 载外, 只受位移荷载(模拟地基差异沉降)作用, 鉴于 轨道部分荷载不大, 对模型变形影响不显著, 故不作 考虑; (4)只考虑路堤地基差异沉降地段的有限部分, 且只考虑模型的垂向差异变形, 不计其水平方向变 形, 故模型左右端只设水平向约束, 垂向不设约束, 如图 2 所示; (5)地基差异沉降渐变模式采用正弦函数 曲线描述.

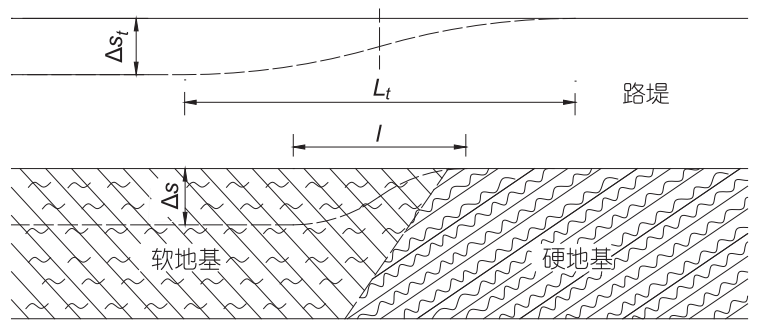

图 1 路堤地基差异沉降模式示意图

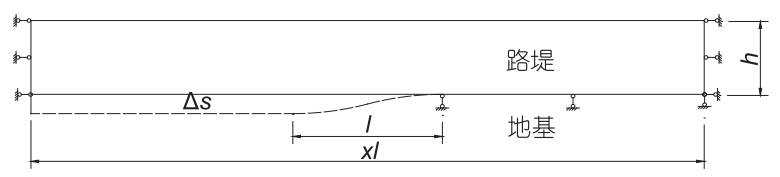

图 2 有限元计算模型示意图(渐变式)
模型计算长度 $x l$ 均取 $100 \mathrm{~m}$. 模型计算高度 $h$ 取 $3,6,9 \mathrm{~m}$; 地基差异沉降渐变段长度 $l$ 取值范围为 (0 10)h. 路堤填料参数如表 1 所列, 其中, 基床表层 厚度为 $0.4 \mathrm{~m}$, 基床底层厚度为 $2.3 \mathrm{~m}^{[6]}$, 填料剪胀角 $\Psi$ 取 $0.95 \varphi$ ( $\varphi$ 为内摩擦角). 数值计算采用 ABAQUS 有限元软件进行.

\section{3 基于土工离心模型试验的有限元计算校正}

提取了西南交通大学陈虎等人相应的土工离心 模型试验部分数据 ${ }^{[11]}$, 对有限元计算进行了校正. 针 对离心试验施加的位移荷载条件, 采用了线性函数 模拟渐变式地基的差异沉降.

为了保证填料剪胀角取值的合理性, 对错台式 和渐变式计算模型进行试算. 试算结果表明: 在路基 小变形情况下, 填料没有发生屈服时, 剪胀角取值对 计算影响不大; 但填料屈服以后, 剪胀角取值对计算 影响较大. 当 $\Psi$ 取值为 $0.95 \varphi$ 时, 计算数据和离心模 型试验结果较接近, 如图 3 所示. 图中, $x$ 为模型横向 坐标, $\Delta s_{t}$ 为路基面差异沉降, $\Delta s$ 为地基差异沉降.

基于以上分析, 后续计算中的填料剪胀角 $\Psi$ 统 一取为 $0.95 \varphi$. 图 4 为 $\Psi=0.95 \varphi$ 时, 有限元计算和离 心模型试验数据对比结果, 二者差异情况如表 2 所列, 其中 $R^{2}$ 为相关指数 ${ }^{[12]}$, 按下式计算:

$$
R^{2}=1-\sum_{t=1}^{N}\left(\Delta s_{t}^{\prime}-\Delta \hat{s}_{t}^{\prime}\right)^{2} / \sum_{t=1}^{N}\left(\Delta s_{t}^{\prime}-\Delta \vec{s}_{t}^{\prime}\right)^{2},
$$

\section{表 1 路堤填料计算参数}

\begin{tabular}{|c|c|c|c|c|c|}
\hline 路堤结构 & $\begin{array}{c}\text { 重度 } \\
\gamma\left(\mathrm{kN} \mathrm{m}^{-3}\right)\end{array}$ & $\begin{array}{c}\text { 泊松比 } \\
v\end{array}$ & $\begin{array}{c}\text { 变形模量 } \\
E(\mathrm{MPa})\end{array}$ & $\begin{array}{l}\text { 黏聚力 } \\
c(\mathrm{kPa})\end{array}$ & $\begin{array}{c}\text { 内摩擦角 } \\
\varphi\left(^{\circ}\right)\end{array}$ \\
\hline 基床表层 & 22 & 0.25 & 120 & 80 & 40 \\
\hline 基床底层 & 21 & 0.27 & 80 & 50 & 38 \\
\hline 基床以下路堤 & 20 & 0.30 & 45 & 30 & 36 \\
\hline
\end{tabular}

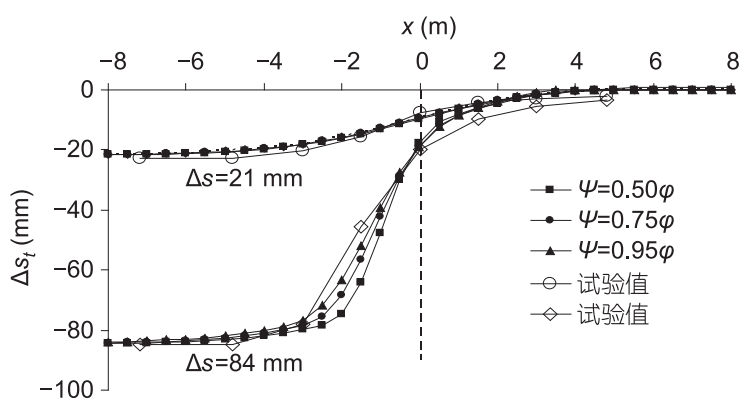

图 $36 \mathrm{~m}$ 高错台式模型剪胀角取值对有限元计算的影响 

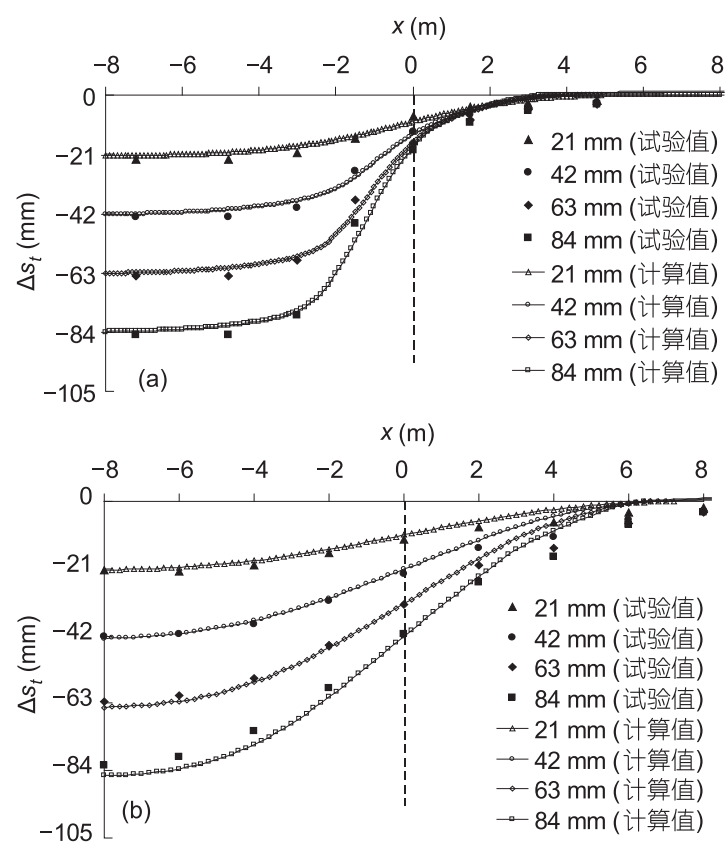

图 4 离心模型试验与有限元计算对比

(a) $h=6 \mathrm{~m}, l=0 \mathrm{~m}$; (b) $h=6 \mathrm{~m}, l=8 \mathrm{~m}$

式中, $\Delta s_{t}^{\prime}$ 为离心模型试验数据; $\Delta \hat{s}_{t}^{\prime}$ 为有限元计算 数据; $\Delta \vec{s}_{t}^{\prime}$ 为离心模型试验数据均值.

由表 2 可以看出, $\Psi=0.95 \varphi$ 时, 有限元计算与离 心模型试验数据吻合较好.

\section{3 路堤地基差异沉降扩散特性及传递规律 分析}

\section{1 路基面不均匀变形影响范围及斜率表征}

路基面不均匀变形斜率指路基面不均匀变形曲 线上相邻两点之间对应的割线斜率, 即路基面上两 点之间的不均匀变形纵坡坡度, 用 $k_{t}$ 表示, 其最大值 记为 $k_{t, \text { max }}$. 当路基面不均匀变形斜率 $k_{t}$ 大于其限值 $m$ 时，对应的区域即为路基面受到的有效影响范围，简

\section{表 2 有限元计算与离心模型试验数据比较}

\begin{tabular}{|c|c|c|c|c|c|c|}
\hline 地基差异 & $h=3$ & $h=6$ & $h=9$ & $h=6$ & $h=6$ & $h=6$ \\
\hline 沉降 (m) & $l=0$ & $l=0$ & $l=0$ & $l=4$ & $l=8$ & $l=12$ \\
\hline$\Delta s(\mathrm{~mm})$ & $R^{2}$ & $R^{2}$ & $R^{2}$ & $R^{2}$ & $R^{2}$ & $R^{2}$ \\
\hline 21 & 0.9758 & 0.9548 & 0.8760 & 0.9888 & 0.9250 & 0.9864 \\
\hline 42 & 0.9726 & 0.9791 & 0.9317 & 0.9886 & 0.9600 & 0.9911 \\
\hline 63 & 0.9702 & 0.9853 & 0.9448 & 0.9900 & 0.9755 & 0.9944 \\
\hline 84 & 0.9649 & 0.9876 & 0.9476 & 0.9894 & 0.9797 & 0.9950 \\
\hline
\end{tabular}

称路基面有效影响范围, 用 $L_{t}$ 表示. 有限元计算表明, 在地基差异沉降为小变形情况下，两种模型的路基 面不均匀变形曲线均呈“S”形，和文献[8]相似，如图 5 所示. 该曲线的最大特点是中间存在斜率最大的拐 点 $\mathrm{C}$, 斜率从 $\mathrm{C}$ 点向左右两侧逐渐减小, 最后趋于 0 . 因此, 可利用路基面不均匀变形曲线的斜率找出路 基面有效影响范围及其对应的曲线特征点. 此处所 指的路基面不均匀变形曲线斜率和文献[13]中提及 的“切线坡度”(切线斜率)相近.

\subsection{1 路基面不均匀变形曲线特征点位置与斜率}

斜率分为切线斜率和割线斜率, 割线斜率按 (2) 式计算, 其中 $\Delta x, \Delta y$ 为曲线上任意两点之间的横、 纵坐标增量值. 当 $\Delta x \rightarrow 0, k=\lim _{\Delta x \rightarrow 0}(\Delta y / \Delta x)$ 即为切线 斜率, 为对应的函数曲线在某点的导数值.

$$
k=\Delta y / \Delta x .
$$

将路基面不均匀变形曲线上邻近两点 $\mathrm{I}\left(x_{i}, y_{i}\right)$, $\mathrm{J}\left(x_{j}, y_{j}\right)$ 的割线斜率 $k_{i j}$ (即不均匀变形斜率)近似等效为 该曲线的切线斜率, 并以此来近似确定其特征点 $\mathrm{C}$, $\mathrm{E}, \mathrm{F}$ 的位置, 如图 5 所示, 图中的点 $\mathrm{E}, \mathrm{F}$ 为 $k_{i j}$ 达到路 基面不均匀变形斜率限值时对应的边界点.

由(2)式可得

$$
k_{i j}=\frac{y_{j}-y_{i}}{x_{j}-x_{i}},
$$

(3)式的物理意义为路基面上 I, J 两点之间的不均匀 变形纵坡坡度值。

\subsection{2 路基面不均匀变形影响范围}

当路基面不均匀变形斜率 $k_{i j}$ 满足(4)式时, 可认 为地基差异沉降引起的路基面不均匀变形不会对高 速行车的安全平稳性造成影响. 因此, 可认为路基面 不均匀变形曲线中不满足(4)式的点所对应的区域即

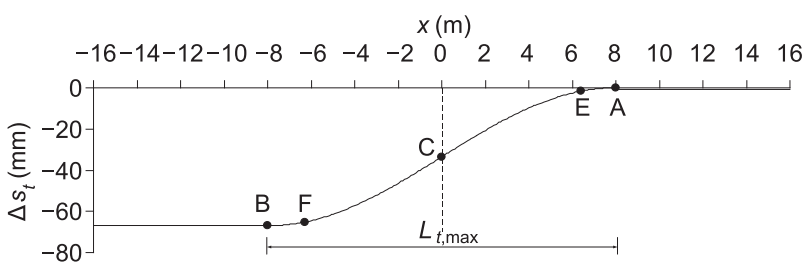

图 5 路基面不均匀变形曲线及特征点位置示意图 
为路基面不均匀变形有效影响范围.

$$
\left|k_{i j}\right| \leqslant m,
$$

式中, $m$ 为与行车安全平稳性有关的限值, 可认为是 路基面不均匀变形斜率(纵坡)限值.

由此可以找出“S”形曲线中 $\left|k_{i j}\right|=m$ 时对应的点 $\mathrm{E}$ 和 $F$, 该两点之间对应的范围即为路基面的有效影响 范围 $L_{t}$, 即

$$
L_{t}=x_{\mathrm{E}}-x_{\mathrm{F}},
$$

式中, $x_{\mathrm{E}}, x_{\mathrm{F}}$ 分别为路基面变形曲线上 $\mathrm{E}, \mathrm{F}$ 两点的横 坐标.

当 $m \rightarrow 0$ 时, 路基面的有效影响范围出现最大 值 $L_{t, \text { max }}$, 相应的区域(A, B 两点之间范围)即为路基面 的最大影响范围.

$$
L_{t, \max }=x_{\mathrm{A}}-x_{\mathrm{B}} .
$$

\subsection{3 路基面不均匀变形斜率限值}

目前，国内外高速铁路对线路不平顺控制的技 术指标多为轨面折角限值 $\theta$. 由于线路纵向呈带状 分布, 在较大范围内轨面和路基面不均匀变形基本 一致, 故近似取路基面不均匀变形斜率限值 $m$ 为相 应的轨面折角限值 $\theta$.

对于高速铁路, 当线路标准不同(行车速度 $V$ 不 同)时, 轨面折角 $\theta$ 的取值是不同的. 文献 $[14,15]$ 建 议: $V=250 \mathrm{~km} / \mathrm{h}$ 时, $\theta$ 可取 $3 / 1000 ; V=350 \mathrm{~km} / \mathrm{h}$ 时, $\theta$ 可取 2/1000. 文献[16]则指出: 行车速度 $V$ 为 $250,350 \mathrm{~km} / \mathrm{h}$ 时, $\theta$ 应控制在 $3 / 1000,1.5 / 1000$ 范围 内. 而我国现行规范规定: 对于无砟轨道高速铁路, 不均匀沉降造成的折角应不大于 $1 / 1000^{[6]}$.

据此, 在参考已有文献及工程经验的基础上, 分别取折角限值为: $V=250 \mathrm{~km} / \mathrm{h}$ 时, $m=3 / 1000$; $V=300 \mathrm{~km} / \mathrm{h}$ 时, $m=2 / 1000 ; V=350 \mathrm{~km} / \mathrm{h}$ 时, $m=$ $1 / 1000$.

\section{2 计算数据分析}

\subsection{1 地基差异沉降传递扩散规律}

在小变形情况下, 经过分析发现, 地基差异沉降 $\Delta s$ 在路堤中的扩散形态和范围受地基差异沉降渐变 段长度 $l$ 与路堤高度 $h$ 的比值影响. 当 $l / h \leqslant 1$ 时, $\Delta s$
在路堤中扩散最为明显, 差异沉降等值线图大致呈 倒钟形分布. 此后, 随着 $l$ 的增加 $\Delta s$ 在路堤中扩散程 度逐渐减弱, 在 $l / h \geqslant 3 \sim 5$ 以后, 地基差异沉降在路堤 中几乎无扩散趋势, 如图 6 所示, 图中垂向位移单位 为 $\mathrm{mm}$. 同地基差异沉降 $\Delta s$ 在路堤中扩散规律一样, 路基面不均匀变形 $\Delta s_{t}$ 和地基沉降差异程度也受 $l / h$ 的影响, 且随 $l / h$ 的增大而减小. 当 $l / h$ 达到一定值时, $\Delta s_{t}$ 和 $\Delta s$ 近似一致, 此时地基差异沉降在路堤高度方 向的扩散不显著

表 3 列出了路堤高度分别为 $3,6,9 \mathrm{~m}$, 路基面 最大不均匀变形斜率不大于 $6 / 1000$ 时, 路基面不 均匀变形曲线和地基差异沉降曲线差异情况. 为了 更好的反应这两条曲线之间的差异程度, 选用二者 对应的斜率曲线作为对比, 其中 $R_{k}^{2}$ 为斜率曲线相关 指数.

以路基面不均匀变形 $\Delta s_{t}$ 曲线和地基差异沉降 $\Delta s$ 曲线最大斜率相对差异小于 $5 \%$ 为标准, 可近似认为 $l / h=3.5$ 时路基面与路堤底部变形一致. 当 $l / h=$ (4.5 5)时, $\Delta s_{t}$ 曲线和 $\Delta s$ 曲线最大斜率相对差异已小 于 $1 \%$. 这与地基差异沉降在路堤中的扩散规律完全 吻合.
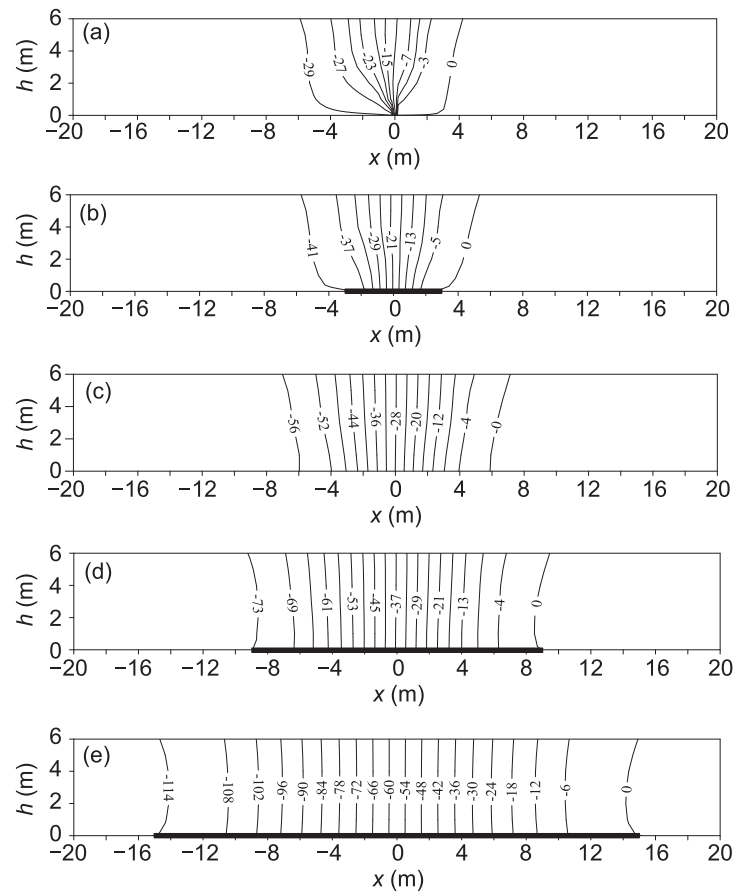

图 6 垂向位移等值线图 $\left(k_{\max }=6 / 1000\right)$

(a) $l=0$; (b) $l=1 h$; (c) $l=2 h$; (d) $l=3 h$; (e) $l=5 h$ 
罗强等: 高速铁路路堤传递地基差异沉降特性及控制限值研究

表 3 路基面不均匀变形曲线与地基差异沉降曲线差异比较

\begin{tabular}{lccccccc}
\hline \multicolumn{1}{c}{$l / h$} & 2 & 2.5 & 3 & 3.5 & 4 & 4.5 & 5 \\
\hline $\begin{array}{l}\text { 最大斜率 } \\
\text { 相对差异 }(\%)\end{array}$ & $22.08 \sim 23.41$ & $11.68 \sim 12.14$ & $6.03 \sim 6.55$ & $2.72 \sim 3.43$ & $0.94 \sim 1.63$ & $0.01 \sim 0.61$ & $0 \sim 0.16$ \\
$R_{k}^{2}$ & $0.9284 \sim 0.9812$ & $0.9660 \sim 0.9937$ & $0.9822 \sim 0.9975$ & $0.9901 \sim 0.9991$ & $0.9938 \sim 0.9996$ & $0.9958 \sim 0.9998$ & $0.9969 \sim 0.9999$ \\
\hline
\end{tabular}

\subsection{2 路基面不均匀变形规律}

根据路基面不均匀变形曲线特性，可用 $k_{t, \text { max }}$ 来 反映路基面垂向不均匀变形程度, 用 $L_{t}$ 来反应路基 面受到的纵向扰动范围. 计算分析表明, 路基面不均 匀变形程度受地基差异沉降 $\Delta s$, 地基差异沉降渐变 段长度 $l$, 路堤高度 $h$ 等因素影响.

当计算模型 $h$ 和 $l$ 一定时, 路基面的最大不均匀 变形斜率 $k_{t, \text { max }}$ 随 $\Delta s$ 的增加而增大, 且在 $\Delta s$ 较小时 几乎呈线性趋势增加, 如图 7 所示; 而路基面有效影 响范围 $L_{t}$ 随 $\Delta s$ 的增加而呈非线性趋势增加, 增加幅 度逐渐减小, 如图 8 所示.

当 $h$ 和 $\Delta s$ 一定时, 路基面的最大不均匀变形斜 率 $k_{t, \text { max }}$ 随地基差异沉降渐变段长度 $l$ 增加而减小, 当

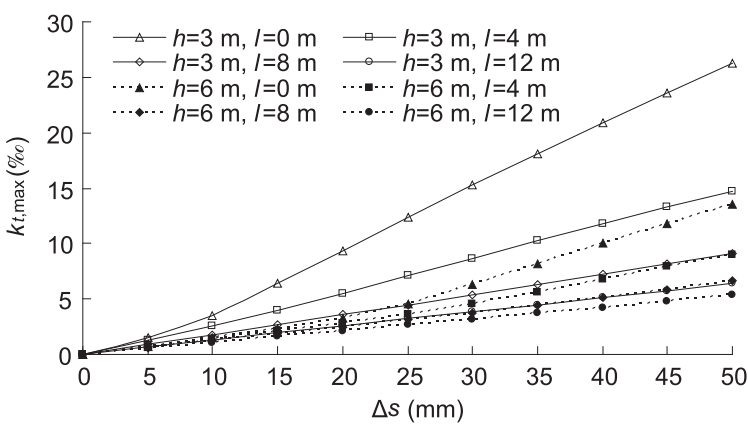

图 $7 \boldsymbol{k}_{t, \mathrm{max}}-\Delta s$ 曲线

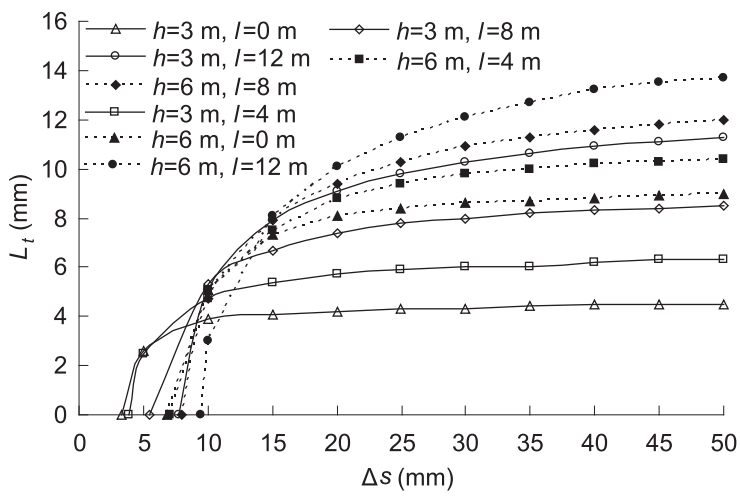

图 $8 L_{t}-\Delta s$ 曲线 $(m=1 / 1000)$ $l=0 \mathrm{~m}$ 时, $k_{t, \text { max }}$ 最大, 这说明设置地基差异沉降渐变 段有利于减缓路基面的不均匀变形纵坡坡度，即减 小地基差异沉降对路基面的垂向扰动程度，且 $l$ 越长 对减缓路基面的不均匀变形纵坡坡度越有利，如图 9(a)所示; 当 $l$ 和 $\Delta s$ 不变时，且 $l / h<3 \sim 5$ 时，路基面变 形曲线的最大不均匀变形斜率 $k_{t, \text { max }}$ 随路堤高度 $h$ 的 增加而减小, 这说明同一地基差异沉降下, 路堤越高, 路基面的不均匀变形纵坡坡度越缓，地基差异沉降 对路基面的垂向扰动程度越小，如图 9(b)所示.

地基差异沉降 $\Delta s$ 一定时, 路基面的最大影响范 围 $L_{t, \text { max }}$ 随地基差异沉降渐变长度 $l$ 或路堤高度 $h$ $(l / h<3 \sim 5)$ 的增大而增加，而路基面的有效影响范围 $L_{t}$ 与地基差异沉降大小密切相关.

当 $\Delta s$ 大于一定程度, $h$ 和 $\Delta s$ 不变时, 路基面的 有效影响范围 $L_{t}$ 随地基差异沉降渐变段长度 $l$ 增加而 增大, 地基差异沉降渐变段长度 $l=0 \mathrm{~m}$ 时, $L_{t}$ 最小, 这 说明在路堤底部增设地基差异沉降渐变段使地基差 异沉降对路基面的纵向扰动范围加大，且 $l$ 越长越显 著, 具体情况如图 10(a)所示; 当 $\Delta s$ 大于一定程度, $l$ 和 $\Delta s$ 不变, 且 $l / h<3 \sim 5$ 时, 路基面的有效影响范围 $L_{t}$ 随路堤高度 $h$ 的增加而增大，这说明在同一地基差异 沉降下, 路堤越高, 地基差异沉降对路基面的纵向扰 动范围越大, 具体情况如图 10(b)所示.

当地基差异沉降 $\Delta s$ 很小时, 路基面的有效影响 范围 $L_{t}$ 变化规律表现出不同的特征. 如：路堤高 $h=6$ $\mathrm{m}$, 路堤底部施加的差异沉降 $\Delta s$ 为 $10 \mathrm{~mm}$ 时, 地基差 异沉降渐变段长度 $l$ 为 $0,4,8,12 \mathrm{~m}$ 的渐变式计算模
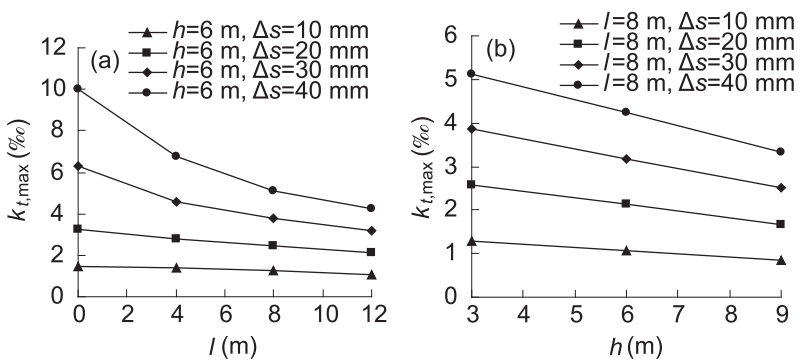

图 $9 k_{t, \text { max }}-l(a)$ 与 $k_{t, \text { max }}-h(b)$ 曲线 

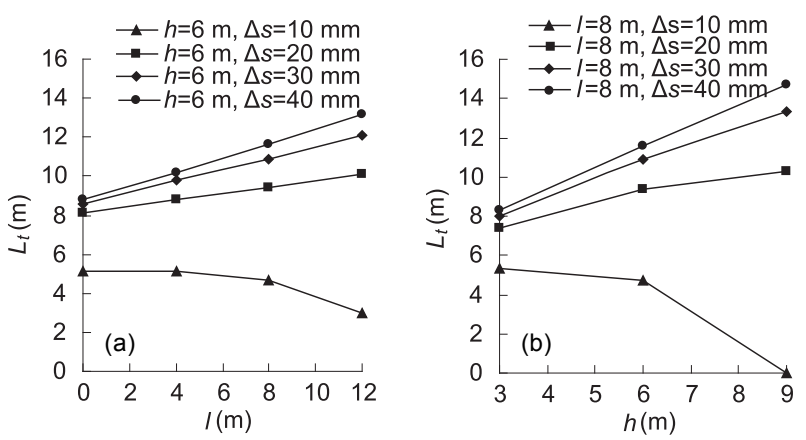

图 $10 L_{t}-l(a)$ 与 $L_{t}-h(b)$ 曲线 $(m=1 / 1000)$

型对应的路基面有效影响范围 $L_{t}$ 分别为 5.1, 5.1, 4.7, $3.0 \mathrm{~m}$. 当 $l$ 一定, $\Delta s$ 很小时, 路基面的有效影响范围 $L_{t}$ 变化规律也会出表现出上述特征, 但控制因素是路 堤高度 $h$, 具体情况可见图 10.

\section{4 基于路基面不均匀变形限值的路堤地基 差异沉降控制标准}

计算分析发现, 地基差异沉降很小时, 路基面最
大不均匀变形斜率 $k_{t, \text { max }}$ 小于给定的指标 $m$, 即地基 差异沉降对路基面的扰动可忽略不计. 这就说明, 对 于一种地基差异沉降模型, 满足 $k_{t, \mathrm{max}}=m$, 可得地基 差异沉降临界值, 记为 $\left[\Delta s_{0}\right]$.

表 4 列出了以 $k_{t, \max }=m$ 为评价指标的各模型对应 的 $\left[\Delta s_{0}\right]$. 从表中可看出, 当路堤高度 $h$ 和地基差异沉 降渐变段长度 $l$ 一定时, $\left[\Delta s_{0}\right]$ 随 $m$ 的增加而增大, 且 $l \geqslant 6 \mathrm{~m}$ 时呈线性递增趋势. 当 $m$ 相同, $\left[\Delta s_{0}\right]$ 随 $l$ 及 $h$ 的变化规律如图 11 所示. 其中, $l=0 \mathrm{~m}$ 时, $\left[\Delta s_{0}\right]$ 最小, 其值可用(7)式近似计算, $h$ 单位取 $\mathrm{mm}$.

$$
\left[\Delta s_{0}\right]_{\min }=0.548 m^{0.924} h^{1.02} .
$$

当 $l \geqslant(3 \sim 5) h$ 时, 路堤底部和路基面的变形基本 一致, $\left[\Delta s_{0}\right]$ 可以由前面假设的地基变形模式函数直接 推出, 可以按 $(8)$ 式计算

$$
\left[\Delta s_{0}\right]=2 \mathrm{~lm} / \pi \text {. }
$$

若以 $k_{t, \mathrm{max}}=m$ 作为评价标准, 得出的地基差异沉 降限值过于保守. 可采用路基面不均匀变形斜率均 值 $\bar{k}_{t}=m$ 作为评价标准得出地基差异沉降限值, 其可

\begin{tabular}{|c|c|c|c|c|c|c|c|c|c|c|c|c|c|c|c|c|c|}
\hline \multirow{2}{*}{$\begin{array}{c}\text { 路堤高度 } \\
h(\mathrm{~m})\end{array}$} & \multirow{2}{*}{$m$} & \multicolumn{16}{|c|}{ 地基差异沉降渐变段长度 $l(m)$} \\
\hline & & 0 & 2 & 4 & 6 & 8 & 10 & 12 & 14 & 16 & 18 & 20 & 22 & 24 & 26 & 28 & 30 \\
\hline \multirow{3}{*}{3} & $1 / 1000$ & 3.3 & 3.5 & 3.9 & 4.7 & 5.5 & 6.6 & 7.7 & 8.9 & 10.1 & 11.4 & 12.7 & 13.9 & 15.2 & 16.5 & 17.8 & 19.0 \\
\hline & $2 / 1000$ & 6.6 & 7.0 & 7.9 & 9.3 & 11.1 & 13.3 & 15.5 & 17.9 & 20.3 & 22.8 & 25.4 & 27.9 & 30.4 & 33.0 & 35.5 & 38.0 \\
\hline & $3 / 1000$ & 9.0 & 10.1 & 11.9 & 14.0 & 16.8 & 19.9 & 23.2 & 26.8 & 30.5 & 34.3 & 38.1 & 41.9 & 45.7 & 49.5 & 53.3 & 57.0 \\
\hline \multirow{3}{*}{6} & $1 / 1000$ & 6.8 & 6.9 & 7.1 & 7.6 & 8.0 & 8.6 & 9.4 & 10.2 & 11.1 & 12.1 & 13.1 & 14.2 & 15.4 & 16.6 & 17.8 & 19.0 \\
\hline & $2 / 1000$ & 13.3 & 13.7 & 14.2 & 15.0 & 16.1 & 17.3 & 18.8 & 20.5 & 22.3 & 24.3 & 26.3 & 28.5 & 30.8 & 33.1 & 35.5 & 38.0 \\
\hline & $3 / 1000$ & 18.8 & 19.8 & 21.1 & 22.5 & 24.1 & 26.0 & 28.2 & 30.7 & 33.5 & 36.4 & 39.5 & 42.8 & 46.2 & 49.7 & 53.3 & 57.0 \\
\hline \multirow{3}{*}{9} & $1 / 1000$ & 10.0 & 10.1 & 10.3 & 10.5 & 10.9 & 11.4 & 11.9 & 12.6 & 13.3 & 14.0 & 14.9 & 15.8 & 16.7 & 17.7 & 18.7 & 19.8 \\
\hline & $2 / 1000$ & 19.9 & 20.2 & 20.6 & 21.1 & 21.9 & 22.8 & 23.9 & 25.2 & 26.6 & 28.1 & 29.8 & 31.6 & 33.4 & 35.4 & 37.5 & 39.6 \\
\hline & $3 / 1000$ & 28.3 & 29.7 & 30.8 & 31.7 & 32.8 & 34.2 & 35.9 & 37.8 & 39.9 & 42.2 & 44.7 & 47.4 & 50.2 & 53.2 & 56.2 & 59.4 \\
\hline
\end{tabular}

\section{表 4 路堤地基差异沉降限值 $\left[\Delta s_{0}\right](\mathrm{mm})$}
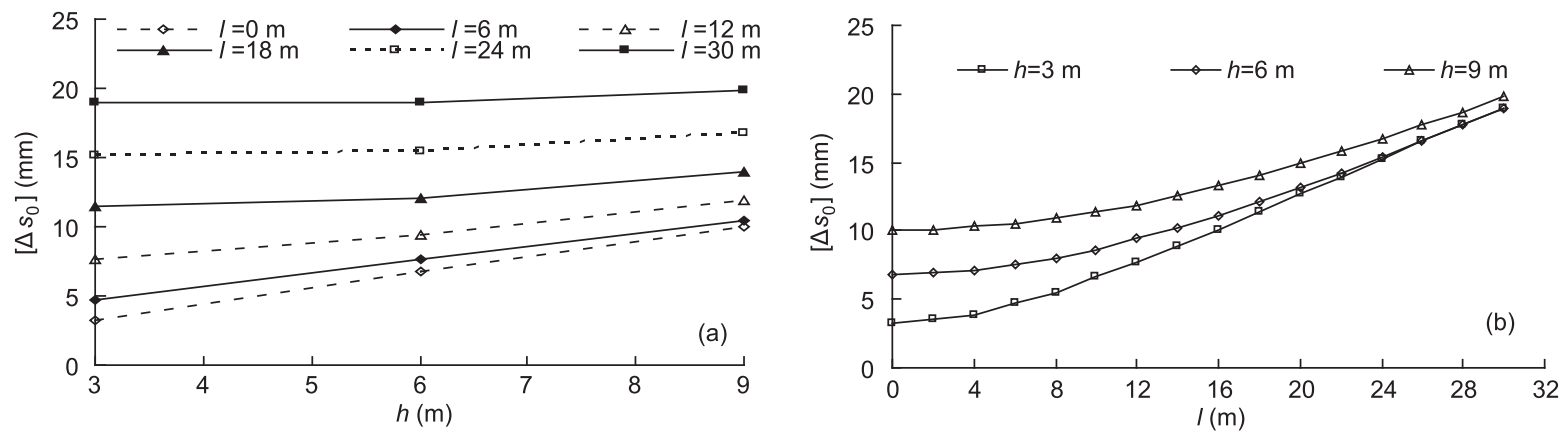

图 $11\left[\Delta s_{0}\right]-h(\mathrm{a})$ 与 $\left[\Delta s_{0}\right]-l(\mathrm{~b})$ 曲线 $(m=1 / 1000)$ 
用 $\Psi_{s}\left[\Delta s_{0}\right]$ 表示. 当 $l / h \leqslant 5$ 时, $\Psi_{s}$ 可由(9)式求出, 当 $l / h$ $>5$ 时, $\Psi_{\mathrm{s}}$ 取为定值 1.57 ,

$$
\Psi_{s}=2-0.086 \frac{l}{h} .
$$

综上, 路堤地基差异沉降限值可统一用(10)式表 示, 以 $k_{t, \max }=m$ 作为评价标准时, $\Psi_{\mathrm{s}}=1$.

$$
[\Delta s]=\Psi_{\mathrm{s}}\left[\Delta s_{0}\right] .
$$

\section{5 结论}

通过对地基差异沉降特性的分析，构建了错台 式和渐变式两种路堤地基差异沉降计算模型, 提出 了路基面的有效影响范围 $L_{t}$ 和路基面不均匀变形斜 率 $k_{t}$ 两个反映路基面不均匀变形程度的指标, 讨论了 地基差异沉降在路堤中传递扩散特征及对路基面不
均匀变形的影响规律, 建立了路基面的有效影响范 围 $L_{t}$, 路基面不均匀变形斜率 $k_{t}$ 的计算方法, 给出了 基于路基面不均匀变形控制标准的路堤地基差异沉 降限值 $[\Delta s]$, 并有以下基本结论.

1）地基差异沉降在路堤中的纵向扩散程度随着 地基差异沉降渐变段长度 $l$ 与路堤高度 $h$ 的比值增大 而减弱. $l / h \geqslant 3 \sim 5$ 以后, 可认为路基面不均匀变形与 地基差异沉降趋于一致.

2) 在 $l / h<3 \sim 5$ 情况下，随着地基差异沉降渐变段 长度 $l$ 或路堤高度 $h$ 的增加, 地基差异沉降对路基面 的垂向扰动程度逐渐减小, 纵向扰动范围相应增大.

3) 地基差异沉降限值 $[\Delta s]$ 与路基面不均匀变形 斜率限值 $m$ 呈正相关性，且在 $l / h<3 \sim 5$ 情况下，随路 堤高度 $h$,地基差异沉降渐变段长度 $l$ 的增加而增大. 当 $l \geqslant 3 \sim 5 h$ 以后, 地基差异沉降限值可通过式 $[\Delta s]=2 \Psi_{s} l m / \pi$ 获得.

\section{参考文献}

1 王其昌. 高速铁路土木工程. 成都: 西南交通大学出版社, 2000. 317

2 中华人民共和国铁道部．高速铁路设计规范(试行)条文说明. 北京：中国铁道出版社, 2009. 118-121, 198-199

3 胡一峰，李怒放．高速铁路无砟轨道路基设计原理．北京：中国铁道出版社, 2010.147

4 卢祖文. 高速铁路基础设施的重大技术问题. 中国铁路, 2004, 8: 11-14

5 赵国堂. 高速铁路无砟轨道结构. 北京: 中国铁道出版社, 2006. 74-76

6 中华人民共和国铁道部．高速铁路设计规范(试行). 北京：中国铁道出版社, 2010

7 罗强. 高速铁路路桥过渡段动力学特性分析及工程试验研究. 博士学位论文. 成都: 西南交通大学, 2003. 153

8 羊晔, 刘松玉, 邓永锋, 等. 软土地基过渡段差异沉降控制标准. 东南大学学报, 2008, 38: 834-838

9 黄晓明. 高速公路路桥(涵)过渡段回填分析方法及应用技术. 北京：人民交通出版社, 2007. 29-30

10 张洪亮，胡长顺，吕文江. 路桥过渡段允许差异沉降计算模型. 交通运输工程学报, 2005, 5: 19-23

11 陈虎. 基于离心模型试验的路堤地基不均匀沉降扩散机理及传递规律分析. 高速铁路不同结构物均匀过渡技术措施的试验研究分报 告之十. 2010. 32-43

12 费业泰. 误差理论与数据处理. 第 6 版. 北京: 机械工业出版社, 2010. 149-150

13 刘萌成. 桥台后回填差异沉降控制标准及设计方法研究. 博士学位论文. 南京: 东南大学, 2005.40-47

14 王其昌，蔡成标，罗强，等. 高速铁路路桥过渡段轨道折角限值的分析. 铁道学报, 1998, 20: 109-113

15 罗强, 蔡英, 翟婉明. 高速铁路路桥过渡段的动力学性能分析. 工程力学, 1999, 16: 65-70

16 陈善雄，宋剑，周全能，等. 高速铁路沉降变形观测评估理论与实践. 北京：中国铁道出版社, 2010. 72-75 


\title{
Analysis on conduction characteristics from embankment and control limits of foundation differential settlement for high speed railway
}

\author{
LUO Qiang, LI Tie, WANG JiaMin, CHEN Hu \& LONG LiBin \\ MOE Key Laboratory of High-speed Railway Engineering, Southwest Jiaotong University, Chengdu 610031, China
}

In order to find the differential settlement transfer and diffusion characteristics for high speed railway, with the help of finite element method, the mapping relationship of the differential settlement and inhomogeneous deformation of the subgrade surface is analyzed. On the basis of geotechnical centrifuge model test correction, discuss how the factors such as foundation differential settlement mode and embankment height affect the inhomogeneous deformation of the subgrade surface. The research show that, the proliferation degree of differential settlement decrease with the ratio of the gradient length of foundation differential settlement to the embankment height increase. When the ratio is greater than 3 to 5, the foundation differential settlement and the inhomogeneous deformation of subgrade surface have a good consistency. The inhomogeneous deformation of subgrade decreases with the embankment height and the gradient length of foundation differential settlement increase. Based on the uneven subgrade surface deformation limits, the foundation differential settlement control standard is put forward. It enriches the high speed railway embankment settlement deformation control technology index system.

high speed railway, differential settlement, conduction diffusion characteristics, deformation uneven, control limits, finite element method

doi: 10.1360/N092014-00091 